\title{
The Effects of Savings Culture and Government Policy in Instilling the Habit of Savings:
}

\author{
Evidence from a Survey of Public Sector Employees
}

\author{
Nur Khairina Muhamad Husin*, Ahmad Martadha Mohamed \\ School of Government \\ Universiti Utara Malaysia \\ Sintok, Kedah, Malaysia \\ *nkhairina29@yahoo.com, martadha@uum.edu.my
}

\begin{abstract}
The aim of this study is to understand the factors that influence the attitude towards savings among Malay employees in the public sector in Malaysia. The research study has focused on both internal and external factor in understanding the influence the attitude towards savings among the employees. The internal factor in this study is savings behavior and savings culture while, the external factor is the government policy. The result of the survey that has been conducted on 769 respondents (Malay employees working in Malaysia public sector). The analysis was made using advanced multivariate statistical software of Structural Equation Modelling (SmartPLS v3). The result of the analysis found that $R 2$ value of the model is 0.306 which indicates that the developed model has a substantial impact on the attitude towards savings. Based on the model, savings culture is the most prominent in exhibiting effect on the attitude towards savings.
\end{abstract}

Keywords-government policy, savings culture, savings behavior, attitude towards savings

\section{INTRODUCTION}

The rapid growth of the economic requires individual to save more. As mentioned by Jean-Paul [1], savings can be referred as the resources that are available for future use either for emergency, life cycle needs or investment purposes. In spite of many definitions that cover savings term, the general definition is the efforts to accumulate financial and nonfinancial assets, which to be used for future consumption or production [2]. The working employees, which have fixed income should be capable to engage with good savings behavior. This is because Foster [3] has indicated that the employees with income need to have good progress towards having an active savings.

The individual's intention to save money is depending on the intention and that intention is believed to be temporary [4]. In addition to this, it is believed that most of the time the individual's attitude towards savings will only being performed if they seek for self-improvement and they initiate the action to save money. In another study conducted by Chudzian et al. [5] by gathering the opinion from young Georgians, the result reveals that most of them are willing to save if they have intention to live a better life in the future. Thus, it requires a motive and purpose to live happily with sufficient amount of money in the future. While referring to a report by Dolan [6], the performance of individual's behavior is influenced by government. The government have potential to be more effective in shaping individual's behavior towards savings.

According to Dolan [6], in achieving government objective to encourage individuals to save more, policy makers should come out with good instruments and regulations to compel individuals to act in desired ways. The use of tools such as incentives and information to encourage savings behavior can bring success in changing minds of the individuals. There were about more than 50 percent of Malaysians were unable to save money for their future use [7]. It is mainly due to high commitments, lack of knowledge on how to manage money successfully and the lavish lifestyle cause the arisen problem. In addition to this, based on the survey conducted by Global Financial Literacy Survey 2015, it was found that more than 100,000 Malaysian were declared bankrupt and were actually facing with the issue of one of the highest household debt in Malaysia.

The problem of insufficient savings among Malaysians will not only make their future life in trouble, but will also affect the economic growth of this country. Moreover, this problem will leave them with not enough money to be used during emergency situation as they are not saving enough. These situations, coupled with the pandemic era due to the outbreak of coronavirus are certainly worrisome because it can deteriorate the individual's life, leaving them with no financial security which later can cause lot of social problems. This situation can inhibit the process of national development [8].

Apart from that, the aim of becoming a "high-income status" nation seems to be difficult to achieve if this issue continues. This is because the situation like this will significantly affects the growth of private consumption and slowing the growth rate of the country. With the issue of 
insufficient savings also lead to the weaken of economic of the country because the purchasing power of individuals is declining.

Therefore, this study aims to understand the extent to which government policy as the external factor that affects individuals to save money, especially among the public sector employees in Malaysia. Besides that, this study also focused on the internal factors within the respondent such as savings behavior, savings culture and attitude towards savings. The research objective is to examine the factor of government policy significantly influence attitude towards savings.

\section{LITERATURE REVIEW}

\section{A. Government Policy}

Government policy is referring to an action taken by the government to deal with specific issue related to public and it requires the use of funds, laws and regulatory measures [9]. King [10] and Al-Habil [11] expand this definition to include an action plan to shape and change individual's behavior. Government policy can be considered as a set of system to be ruled [9]. The policy being made have potential to bring about significant changes in savings behavior. The research has found that the legislation of the policy should be strict and should involve coercion to ensure that individuals save money for future use [6]. Even though this approach was seen to bring success in its implementation, Serban [9] has highlighted that this approach was seen to be inappropriate and costly. This is because not all individuals, especially employees who are working in the public sector are the high-income earners. On top of that in a study carried out by Lim et al. [12], it was found that the individual's behavior itself does influence the way people behave towards savings. The trend of spending now and think later has developed the bad attitude towards savings. It should be in the way of save money first and spend the remaining money. With this mentality, it will make them to spend beyond their earning thus, unable to save money on monthly basis [13].

\section{B. Savings Behavior}

Savings behavior can be seen as the continuous behavior often to put aside some money to be used either for emergency, retirement, healthcare expenses or to be invested [1]. It is, therefore, mainly is important plan that can be used during unexpected situation. Savings requires individuals to allocate some amount of money and it need to be actively saved for future use [3]. The issue of having lack of savings among employees may happen because of the rising cost of living, having lots of commitments or bad sending habits. Bernheim and Scholz [14] also revealed that majority of the employees particularly among the baby boomers is relatively low. As a result of this situation, it will negatively impact their retirement life thus, reduce the happiness of enjoying retirement good life. Apart from that, Kramer [15] pointed out that this situation is due to the culture of bad spending habits and lack of financial management skills. This culture has encouraged the habit of excessive spending and lowers the tendency to save. Insufficient amount of savings may occur if there is excessive use of money to make purchase of unimportant things. Often, the extent of insufficient savings has brought a negative impact such as could not afford to live comfortably, children cannot have a better higher education and does not have a comfortable live during retirement [16].

\section{Savings Culture}

The element of norms and values should be included in discussing about the culture. Norms have been defined as [17]. Meanwhile, values can be understood as desirable intentions actual actions that derive from the evaluation about certain activities [18]. Hence, culture that comprises of these two elements can be referred as principles in individual's personal morality [19] and individual's moral obligation [20]. The savings culture on the other hand is about the individual's perception and obligation to put aside money to be used during unexpected situation. Culture does affect the way individuals behave towards money and it was found that savings varies across the countries [21]. While Guin [22] found that savings decision closely related to cultural groups, it still requires the financial planning to be initiated by the individuals himself. Poor financial planning will eventually lead towards bad attitude towards savings. This situation will cause another problem such as stress, social hardship, additional burden in terms of social welfare and bankruptcy [23].

\section{Attitude towards Savings}

The definition of attitude towards savings can be seen from both definitions of attitude and savings. Attitude is referred to a psychological tendency to evaluate a particular entity with some degree of favor or disfavor [24]. Meanwhile, savings is about the changes of wealth [25]. Therefore, it can be understood that attitude towards savings is about an act of allocating some part of the income for future purposes. Most of the time, people have intention to save money [26]. However, they often have little savings due to many factors and this situation will make them feel regret when they have no money to be used during unexpected situation [27].

\section{RESEARCH DESIGN AND METHODOLOGY}

\section{A. Research Philosophy and Design}

This study has utilized the quantitative research method to obtain information from the respondents. A sample of 769 public sector employees from four categories of government sectors; federal government, state government, local government and statutory bodies from northern region of Peninsular Malaysia (Perlis, Kedah, Penang and Perak) has involved to answer the questionnaires. The research data is collected through the distribution of hardcopy to the of public sector agencies with the purpose of examine the relationship between the dependent variable (attitude towards savings) and independent variable (government policy and savings culture) of the public sector employees in Malaysia. The collection of 
the data will be conducted only once by targeting the Malay ethnic who are working in the public sector regardless of the job position.

\section{B. Data Collection Method}

The use of hardcopy questionnaire was made in collecting the data from respondents. In addition to this, the use of secondary data also was made. The data or reports published by the Malaysian Government Agency and Bank Negara were being assessed while conducting this research study. Other than that, some data and information also was obtained from other researchers who have conducted similar study.

\section{Data Analysis Method}

In analyzing data obtained from survey, questionnaire, the use of statistical software (SPSS) will be utilized. The use of this statistical software can bring some advantages such as better data management, wider range of options available and better result can be generated [28]. For the purpose of ensuring there is no violation of the general assumptions, these assumptions have been checked. Apart from that, the reliability test was also being conducted as a measure to see how closely related a set of items are as a group. The analysis of the data was started with the assessment of the demographic profile of respondents and descriptive statistics. Later, in explaining the strength and direction of the linear relationship between the dependent variable and the independent variables, the correlation analysis was conducted for that purpose. The use of Pearson Correlation Coefficient was made in explaining the relationship. In addition to this, the use of PLS-SEM also was made in order to explain the relations between latent variables and their relative manifest variables. The conceptual model showing latent variables and manifest variables is shown in Figure 1. In the figure, the oval shape will represent latent variable meanwhile, the rectangular shape represents manifest variables. Besides that, the demography of the respondents is being presented in Table 1 below.

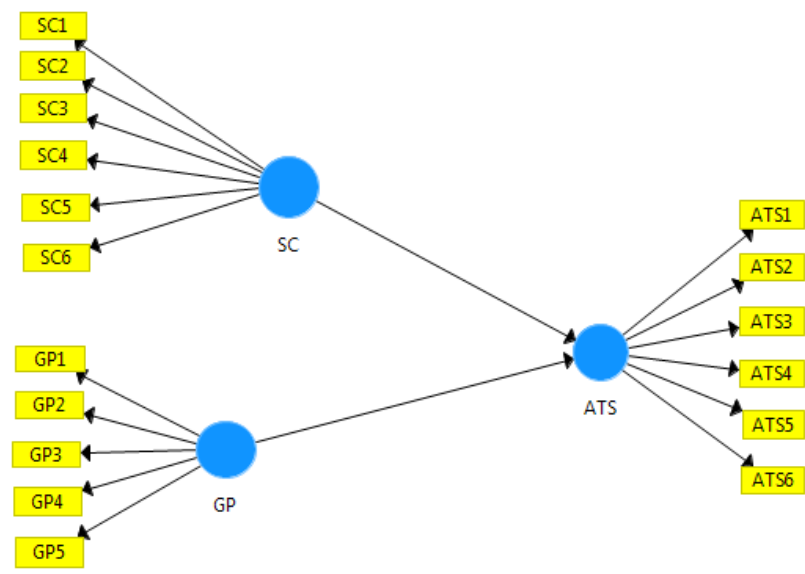

Fig. 1. Conceptual model of government policy and attitude towards savings.
TABLE I. CHARACTERISTICS OF THE RESPONDENTS

\begin{tabular}{|c|c|c|}
\hline Characteristic & Frequency & Percentage \\
\hline \multicolumn{3}{|l|}{ Gender } \\
\hline Male & 302 & 39.3 \\
\hline Female & 467 & 60.7 \\
\hline \multicolumn{3}{|l|}{ Age } \\
\hline 25 or below & 61 & 7.9 \\
\hline $26-35$ & 304 & 39.7 \\
\hline $36-45$ & 254 & 33.0 \\
\hline $46-60$ & 149 & 19.4 \\
\hline \multicolumn{3}{|c|}{ Marital status } \\
\hline Single & 155 & 20.2 \\
\hline Married & 609 & 79.2 \\
\hline Divorced/Separated & 5 & 0.7 \\
\hline \multicolumn{3}{|c|}{ Educational level } \\
\hline SPM/STPM & 264 & 34.3 \\
\hline Diploma & 208 & 27.0 \\
\hline Degree & 238 & 30.9 \\
\hline Masters & 57 & 7.4 \\
\hline $\mathrm{PhD}$ & 2 & 0.3 \\
\hline \multicolumn{3}{|c|}{ Job position } \\
\hline Top management group (JUSA) & 3 & 0.4 \\
\hline $\begin{array}{l}\text { Management and professional group } \\
\text { (grade } 41 \text { - grade } 54 \text { ) }\end{array}$ & 195 & 25.1 \\
\hline Support group (below grade 41) & 571 & 74.3 \\
\hline \multicolumn{3}{|c|}{ Monthly income } \\
\hline RM1,000 - RM2,000 & 177 & 23 \\
\hline RM 2,001 - RM4,000 & 344 & 44.7 \\
\hline RM4,001 - RM6,000 & 180 & 23.4 \\
\hline RM6,001 - RM8,000 & 50 & 6.5 \\
\hline Above RM8000 & 18 & 2.3 \\
\hline
\end{tabular}

Table 1 has indicated that the participants of this survey are competent thus, the data collected is considered valid.

\section{RESULTS AND DISCUSSION}

The conceptual model drawn in SmartPLS Version 3 for simulation work to assess the effect of manifest variables (inhibiting factors) on the attitude toward savings. Various parameters have been used to calculate and assess the simulation of the model. It includes loading, reliability and validity tests. The calculation and assessment will involve 2step process which are calculate the PLS model parameters separately [29]. This process requires the solving out blocks of the measurement model [30]. Another step to be carried out is that estimate the path coefficient of a structural model.

\section{A. Measurement Model Evaluation}

The objective of performing measurement model evaluation is to evaluate the consistency and validity of the manifest variables. It can be evaluated through individual manifest and construct reliability tests. The validity of the variables can be tested through convergent and discriminant validity meanwhile [31], the calculation of standardized outer loadings of the manifest variables can be explained by using individual manifest reliability [32]. The value of outer loading for manifest variable of 0.7 or higher are considered as highly satisfactory, value of 0.5 is considered as acceptable, the value of less than 0.5 cannot be accepted and should be dropped 
[29,32-34]. However, the loading value of less than 0.4 should be accepted [35]. The loading values ranged between 0.4 to 0.7 are needed to be reviewed before elimination [29]. He added if the indicators to be eliminated will increase the composite reliability, an action of discard or maintain the factor should be made. For this study, the cut-off value considered acceptable for outer loading is 0.5 . Considering suggestion by Henseler et al. [29], an iterative process also is adopted for elimination of the manifest variables.

On the other hand, constructed reliability become another step process to calculate the parameter for consistency. It will be evaluated by measuring its Cronbach's alpha and Composite Reliability (CR). The indication of how well a set of manifest variables appraises a single latent construct can be determined by using Cronbach's alpha and CR. Fornell and Larcker [36] indicated that composite reliability has been considered as a best measure of internal consistency compared to Cronbach's alpha. This is due to the reason of composite reliability employs the standardized loadings of the manifest variables. In addition to this, Litwin [37] suggested that the Cronbach's alpha value should be more than 0.7 , while for the composite reliability the value 0 f 0.7 is suggested to be modest [38].

For testing the validity of the variable, it will be tested by using convergent and discriminant validities. As mentioned by Fornell and Larcker [36], the Average Variance Extracted (AVE) test on variables will be carried out to determine the convergent validity. The amount of variance will be determined based on measurement errors being captured from its relative manifest variables. The minimum value of $50 \%$ of the variance is suggested to be captured by latent variable which represents the value of greater than 0.5 [38,39]. The purpose of carrying out discriminant validity test is to confirm the manifest variable in any construct is relevant to the designated latent variable. Chin [33] has stressed on the cross-loading value in latent variable should be higher than that in any other constructs.

TABLE II. Result of MEASUREMENT Model EVALUAtion

\begin{tabular}{|l|l|l|l|l|l|}
\hline Construct & Items & Loadings & AVE & $\begin{array}{c}\text { Composite } \\
\text { Reliability }\end{array}$ & $\begin{array}{c}\text { Cranach's } \\
\text { Alpha }\end{array}$ \\
\hline \multirow{3}{*}{$\begin{array}{l}\text { Savings } \\
\text { Culture }\end{array}$} & SC1 & 0.557 & \multirow{2}{*}{.611} & .901 & .868 \\
\cline { 2 - 3 } & SC2 & 0.865 & & & \\
\cline { 2 - 3 } & SC3 & 0.879 & & & \\
\cline { 2 - 3 } & SC4 & 0.827 & & & \\
\cline { 2 - 3 } & SC5 & 0.881 & & & \\
\cline { 2 - 3 } & SC6 & 0.609 & & & \\
\hline \multirow{4}{*}{$\begin{array}{l}\text { Government } \\
\text { Policy }\end{array}$} & GP1 & 0.742 & .626 & .893 & .849 \\
\cline { 2 - 3 } & GP2 & 0.769 & & & \\
\cline { 2 - 3 } & GP3 & 0.752 & & & \\
\cline { 2 - 3 } & GP4 & 0.851 & & & \\
\cline { 2 - 3 } & GP5 & 0.833 & & & \\
\hline
\end{tabular}

As presented in Table 2, both constructs SC and GP have parametric measurement above the cut off values which is above 0.5. Hence, these two constructs are relevant to the designated latent variable. Apart from that, discriminant validity will also be checked using this model. In checking the discriminant validity, cross loading values will be generated, and those values is presented in Table 3. As shown in the table, the cross-loading values for all manifest variables scores higher values on their latent variable. Therefore, it can be verified that the manifest variables in each construct represent the assigned latent variable testifying the discriminant validity of the model.

\section{B. Structural Model Assessment}

The purpose of conducting structural model assessment is to assess the relationship between exogenous and endogenous latent variables. It can be done by evaluating the value of R2. $\mathrm{R} 2$ value is coefficient of determination meanwhile, $\beta$ value is path coefficient of the model $[31,33]$. The value of $\mathrm{R}$ indicates the variance of endogenous latent variables and $\beta$ value will show the strength of an effect from variables to endogenous latent variables $[40,41]$. In addition to this, in order for a model to be considered as a good model, the value of $\mathrm{R} 2$ of endogenous latent variable should be more than $0.26[42,43]$. From the Table 4 below, it shows that the R2 scores 0.306 . This value is higher than the suggested value, thus, the model is considered to have substantial degree of explained variance of attitude towards savings by inhibiting factors. Next, Table 3 will present the path coefficient values of all latent variables (paths). The comparison of $\beta$ values between all the paths will be made in order to know the path coefficient values for all latent variables. The highest value of $\beta$ indicates the strongest effect of predictor (exogenous) latent variable towards the dependent (endogenous) latent variable [44]. Besides that, the significance level of $\beta$ value needs to be tested by using t-value test. In performing the test, a nonparametric bootstrapping technique will be done in which this bootstrapping technique will compute $\mathrm{t}$-value by creating prespecified number of samples $[33,45,46]$. The acceptable t-values should be 1.65 ( significance level $=10$ percent $), 1.96$ (significance level $=5$ percent), and 2.58 (significance level $=1$ percent) [38]. All these values are for two-tailed test. Hence, Table 4 shows a nonparametric bootstrapping technique generated 5000 samples in order to compute t-values.

TABLE III. RESULT OF CROSS LOADING

\begin{tabular}{|l|l|l|l|}
\hline & \multicolumn{1}{|c|}{ ATS } & \multicolumn{1}{c|}{ GP } & SC \\
\hline ATS1 & 0.721 & 0.317 & 0.271 \\
\hline ATS2 & 0.684 & 0.219 & 0.216 \\
\hline ATS3 & 0.697 & 0.350 & 0.199 \\
\hline ATS4 & 0.768 & 0.393 & 0.548 \\
\hline ATS5 & 0.736 & 0.366 & 0.292 \\
\hline ATS6 & 0.6 .6 & 0.208 & 0.298 \\
\hline GP1 & 0.382 & 0.742 & 0.318 \\
\hline GP2 & 0.309 & 0.769 & 0.304 \\
\hline GP3 & 0.340 & 0.752 & 0.307 \\
\hline GP4 & 0.396 & 0.851 & 0.305 \\
\hline GP5 & 0.357 & 0.833 & 0.297 \\
\hline SC1 & 0.236 & 0.337 & 0.557 \\
\hline SC2 & 0.395 & 0.273 & 0.865 \\
\hline SC3 & 0.385 & 0.295 & 0.879 \\
\hline SC4 & 0.459 & 0.348 & 0.827 \\
\hline SC5 & 0.410 & 0.297 & 0.881 \\
\hline SC6 & 0.224 & 0.320 & 0.609 \\
\hline
\end{tabular}




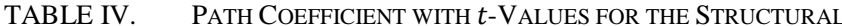
MODEL.

\begin{tabular}{|l|l|l|ll|}
\hline & & Path coefficient $(\boldsymbol{\beta})$ & \multicolumn{1}{|c|}{$\boldsymbol{t}$-value } \\
\hline SC & Savings Culture & 0.342 & 8.315 & \\
\hline GP & Government Policy & 0.322 & 10.212 & \multicolumn{2}{|c}{$\quad \mathrm{P}<0.01$} \\
\hline
\end{tabular}

\section{CONCLUSION}

This study highlighted the attitude towards savings of the Malay employees in the public sector by two inhibiting factors. By using SmartPLS software, these two factors are being grouped and modeled into two categories. Later, these factors were analyzed in order to assess the effect on attitude towards savings. Therefore, this study has come out with several conclusions. Those are as follows,

- A major conclusion drawn from this study is that 11 inhibiting factors have a strong effect on attitude towards savings.

- The value of R2 of the model scores more than 0.26 thus, it can be said that this is a good model to explain variance of attitude towards savings by inhibiting factors.

- The sample size of 769 public sector employees involved in this study was adequate to understand the pattern of savings among the respondents.

- Most significant category of inhibiting factors affecting attitude towards savings among Malay employees working in the public sector in Malaysia is savings culture.

\section{ACKNOWLEDGMENT}

The author would like to thank Ghazali Sahfie Graduate School of Government, Universiti Utara Malaysia and research supervisor, Prof. Dr. Ahmad Martadha Mohamed for the encouragement and support in carrying out this research study. The author also would like to thank all the respondents participating in the survey because without your cooperation and precious time, this study could not be completed. Husin, N. K. M. is thankful to the four categories of government sectors, federal government, state government, local government, and statutory bodies for granting me permission to carryout research work in the government agencies.

\section{REFERENCES}

[1] L. Jean-Paul, "Savings strategies of poor women in Zimbabwe: A socioeconomic perspective," Paper presented at the International Conference on Livelihood, Savings and Debt in a Changing World: Developing Anthropological and Sociological Perspectives, Wageningen, Netherlands, 2001.

[2] C. Campos, "Savings behaviors in rural Mexico," Paper presented at the International Conference on Livelihood, Savings and Debt in a
Changing World: Developing Anthropological and Sociological Perspectives, Wageningen, Netherlands, 2001

[3] A.C. Foster, "Employee participation in savings and thrift plans," Monthly Labor Review, pp. 17-22, 1996.

[4] M. McConnell, "Between intention and action: An experiment on individual savings," Cambridge: Department of Global Health and Population. Harvard School of Public Health, 2012.

[5] J. Chudzian, P. Anioła-Mikołajczak and L. Pataraia, "Motives and attitudes for saving among young Georgians," Economics and Sociology, vol. 8, pp. 165-188, 2015.

[6] P. Dolan, M. Hallsworth, D. Halpern, D. King, and I. Vlaev, "MINDSPACE: Influencing behaviour through public policy. Discussion Paper. Institute for Government," 2010. [Online] Retrieved March 22, 2018, from https://www.instituteforgovernment.org.uk/sites/default/files/publication s/MINDSPACE.pdf

[7] nielseniq.com, "Malaysian consumers actively saving to achieve their financial goals," 2014. [Online] Retrieved January 26, 2016, from http://www.nielsen.com/my/en/press-room/2014/saving-and-investmentstrategies.html

[8] F. Idris, K.S.D. Krishnan, and N. Azmi, "Relationship between financial literacy and financial distress among youths in Malaysia - An empirical study," Malaysian Journal of Society and Space, vol. 9, pp. 106-117, 2013

[9] M. Serban, "Supporting public policy making through policy analysis and policy learning," 2015. [Online] Retrieved March 25, 2018, from http://www.etf.europa.eu/webatt.nsf/0/A490BF6FDAD1B387C1257EB 3005E18D9/\$file/Ex-ante\%20impact\%20assessment.pdf

[10] A. King, "Ideas, institutions and the policies of governments: A comparative analysis, Parts I and II," British Journal of Political Science, vol. 3, pp. 291-313, 1973 .

[11] W. Al-Habil, "Governance and government in public administration," Journal of Public Administration and Policy Research, vol. 3, pp. 123 128, 2011.

[12] W.M. Lim, W.K. Ng, J.H. Chin, and A.W.X. Boo, "Understanding young consumer perceptions on credit card usage: Implications for responsible consumption," Contemporary Management Research, vol. 10 , pp. 287-302, 2014

[13] V.P. Urbis, D. Rintoul, B. Power, and N. Keevy, Young people (12-17 years) \& financial debt. Australia: Commonwealth of Australia, 2008

[14] B.D. Bernheim, and J.K. Scholz, "Do Americans save too little?." Business Review, vol. 9, pp. 3-21, 1993.

[15] L. Kramer, "America's savings crisis: Your spending habit may be to blame. CNBC," 2013. [Online] Retrieved June 5, 201, from http://www.cnbc.com/id/100700580

[16] K. Richman, "La tercera edad: A focus group study on the effects of retirement in Latino families," 2007. [Online] Retrieved June 6, 2016, from

https://latinostudies.nd.edu/assets/95277/original/focus_group_study.pdf

[17] M. Sherif, The psychology of social norms. New York: Harper, 1936.

[18] S.L. Kaushal, and Y. Janjhua, "An empirical study on relationship between personal values and performance values," Himachal Pradesh University Journal, pp. 1-8, 2011.

[19] L. Chan and B. Bishop, "A moral basis for recycling: Extending the theory of planned behaviour," Journal of Environmental Psychology, vol. 36, pp. 96-102, 2013.

[20] W. Abrahamse and L. Steg, "Factors related to household energy use and intention to reduce it: The role of psychological and sociodemographic variables," Human Ecology Review, vol. 18, pp. 30-40, 2011.

[21] C.D. Carroll, B.K. Rhee, and C. Rhee, "Does cultural origin affect saving behavior? Evidence from immigrants," 1998. [Online] Retrieved December 18, 2017, from http://www.nber.org/papers/w6568.pdf

[22] B. Guin, "Culture and household saving," 2017. [Online] Retrieved December $\quad 18, \quad 2017$,

from 
https://www.ecb.europa.eu/pub/pdf/scpwps/ecb.wp2069.en.pdf?21b7b76 0cdef5efc73c409951214a964

[23] K.H. Nga and K.K. Yeoh, "Affective, social and cognitive antecedents of attitude towards money among undergraduate students: A Malaysian study,” Pertanika Journals of Social Sciences \& Humanities, vol. 23, pp. 161-180, 2015.

[24] A.H. Eagly and S. Chaiken, The psychology of attitudes. Texas: Harcourt Brace Jovanovich, 1993.

[25] J. Gali, "Finite horizons, life-cycle savings, and time-series evidence on consumption," Journal of Monetary Economics, vol. 26, pp. 433-452, 1990.

[26] K.E. Warneryd, The psychology of saving: A study of on economic psychology. United Kingdom: Edward Elgar Publishing Limited, 1999.

[27] G. Katona, Psychological economics. New York: Elsevier Scientific Publishing Company, 1975.

[28] S. Campbell and O. Aragon, "Intermediate SPSS," Social Science Research Services, 2013.

[29] J. Henseler, C.M. Ringle, and R.R. Sinkovics, "The use of partial least squares path modeling in international marketing," Advances in International Marketing, vol. 20, pp. 277-319, 2009.

[30] V.E. Vinzi, L. Trinchera, and S. Amato, "PLS path modeling: from foundations to recent developments and open issues for model assessment and improvement," 2010. In Handbook of Partial Least Squares, V. E. Vinzi, W. W. Chin, J. Henseler, and H. Wang, Eds., Springer Handbooks of Computational Statistics, pp. 47-82.

[31] J.F. Hair, M. Sarstedt, C.M. Ringle, and J.A. Mena, "An assessment of the use of partial least squares structural equation modeling in marketing research," Journal of the Academy of Marketing Science, vol. 30, pp. 414-433, 2012.

[32] O. Gotz, K. Liehr-Gobbers, and M. Krafft, "Evaluation of structural equation models using the Partial Least Squares (PLS) approach," 2010. In Handbook of Partial Least Squares, V. E. Vinzi, W. W. Chin, J. Henseler, and H. Wang, Eds., Springer Handbooks of Computational Statistics, pp. 47-82.

[33] W.W. Chin, "The partial least squares approach to structural equation modeling," In Modern Methods for Business Research, G. A. Marcoulides, Ed., pp. 295-336. United States: Erlbaum, Mahwah, 1998.
[34] J.F. Hair, C.B. William, J.B., Barry, and R.E. Anderson, Multivariate data analysis. United States: Prentice Hall, Englewood Cliffs, 2010.

[35] J. Hulland, "Use of Partial Least Squares (PLS) in strategic management research: a review of four recent studies," Strategic Management Journal, vol. 20, pp. 195-204, 1999.

[36] C. Fornell, and D.F. Larcker, "Evaluating structural equation models with unobservable variables and measurement error," Journal of Marketing Research, vol. 18, pp. 39-50, 1981.

[37] M.S. Litwin, How to measure survey reliability and validity. United States: Sage, Thousand Oaks, 1995.

[38] J.F. Hair, C.M. Ringle, and M. Sarstedt, "PLS-SEM: indeed a silver bullet," Journal of Marketing Theory and Practice, vol. 19, pp. 139-151, 2011.

[39] D. Barclay, R. Thompson, and C. Higgins, "The Partial Least Squares (PLS) approach to causal modeling: personal computer adoption and use as an illustration,” Technology Studies, vol. 2, pp. 285-309, 1995.

[40] S. Akter, J.D. Ambra, and R. Ray, "An evaluation of PLS based complex models: the roles of power analysis, predictive relevance and GoF index," Proceedings of the 17th Americas Conference on Information Systems (AMCIS '11), Detroit, Mich, USA, 2011.

[41] C. Lleras, "Path analysis," Encyclopedia of Social Measurement, vol. 3, pp. 25-30, 2005.

[42] J. Cohen, Statistical power analysis for the behavioral sciences. United States: Lawrence Erlbaum Associates, 1988.

[43] J. Cohen, P. Cohen, S.G. West, and L.S. Aiken, Applied multiple regression/correlation analysis for the behavioral sciences (3rd Ed.). United States: Lawrence Erlbaum Associates, 2003.

[44] A.A. Aibinu, and A.M. Al-Lawati, "Using PLS-SEM technique to model construction organizations' willingness to participate in e-bidding," Automation in Construction, vol. 19, pp. 714-724, 2010.

[45] B. Efron and R.J. Tibshirani, An Introduction to the bootstrap, vol. 57 of monographs on statistics and applied probability. United States: Chapman and Hall, 1993.

[46] A.C. Davison and D.V. Hinkley, Bootstrap methods and their application. England: Cambridge University Press, 1997. 